\title{
SOME PHYSICAL EFFICIENCY TESTS ON BENGALESE FOOTBALL GOALKEEPERS
}

\author{
A. K. DE, MD \\ Unit of Sports Medicine and Pulmonary Physiology, Department of Physiology, \\ Institute of Medical Sciences, Banaras Hindu University, \\ VARANASI - 221 005, INDIA
}

\begin{abstract}
Simple anthropometric measurements and physical efficiency tests were conducted on 21 Football Goalkeepers from West Bengal, India. The age of the subjects varied between 18-24 years (av. 21.1). The Vital Capacity (total $\mathrm{ml} / \mathrm{cm} \mathrm{of}$ height, L/m $\mathrm{m}^{2}$ of surface area) and the Peak Expiratory Flow Rate (total, L/cm of height, L/kg of body weight, L/m $\mathrm{m}^{2}$ of surface area, L/age) were noted to be higher in the subjects of the present study than those reported for average healthy Indian population, but lower than values from top Indian athletes. The values of grip strength observed in this study could not be compared because of unavailability of Indian norms. The higher values of physical efficiency tests observed in these subjects in comparison to those of average Indian populations were probably due to training effects.
\end{abstract}

KEYWORDS:

Foo thall goalkeepers; physical efficiency, anthropometry; Vital Capacity; Peak Expiratory Flow Rate; Grip Strength.

\section{INTRODUCTION}

The assessment of physical efficiency of sportsmen is usually performed with the help of a battery of tests. However, Pulmonary Function Tests (PFT) and strength tests, are considered to be important for appraising physical performance capabilities in both general population surveys as well as for athletes. Data on PFT are available on population groups from various parts of India; however, further work on PFT pertaining to athletes (both men and women) are very scanty. Physiological tests on Indian athletes have been conducted by a few authors (Malhotra, et al, 1972a, b; De, 1978). The performance level of participants in various sports and its correlation with factors such as body size, shape and composition have been attempted (Cureton, 1951; Behnke and Royce, 1966; Novak, et al, 1968; Sprynarova and Parizkova, 1971). A number of studies have been conducted on champion athletes of different countries and a correlation was tried with the performance level and various physiological parameters (Newman, et al, 1962; Saltin and Åstrand, 1967; Di-Prampero, 1970; De, et al, 1978). These include few studies to compare the efficiency level between the trained and untrained groups of subjects. From these studies it is easy to appreciate that the different skills require different training schedules and levels of fitness. In the team sports this will also apply to players in different position. Thus, the present study was undertaken to assess the physical performance level on a group of football goalkeepers which will be useful for comparison among intra- or inter-game participants as well as to search for the modification of the training and conditioning schedules.

\section{SUBJECTS AND METHODS}

The present study was conducted on $\mathbf{2 1}$ male football goalkeepers from Wari Club, Calcutta, in the month of April. They were all from similar socio-economic backgrounds and aged between 18-24 years (av. 21.1). All were training to be goalkeepers and had played for 3-5 years in different divisions of the Indian Football Association. The data recorded were height, weight, vital capacity (VC) - using Wright's respirometer - peak expiratory flow (PEFR) Wright's peak flow meter - and grip strength (GS) - using a hand dynamometer. The Surface Area (SA) was determined by DuBois nomogram. The best of three trials of VC and the highest of five readings for PEFR were accepted and the results were presented in BTPS and shown in Table $\mathrm{I}$.

\section{DISCUSSION}

In the present study on Bengalese goalkeepers, the mean height and weight is lower than recorded by De (1978) for physical education students. This may be a racial and environmental difference as the previous study was on people from Uttar Pradesh, yet compared with South Indians (Milledge, 1965) the Bengalese are taller. This is also reflected in the VC data. If it is appreciated that there are good correlations between height and VC and $V C$ is recalculated per unit height, the corrected $V C$ is very similar in the three groups but lower than in the survey of top class Indian athletes reported by Malhotra, et al (1972) suggesting a specific sports difference between goal keepers. This may be the result of selection of sport and performer or of lower physical activity needs in goalkeepers compared with other athletes. 


\section{TABLE I}

Results of simple anthropometric, VC, PEFR and GS measurements of Indian Football goalkeepers.

Age (years)

Height $(\mathrm{cm})$

Weight (kg)

Surface Area $\left(\mathrm{m}^{2}\right)$

Vital Capacity (litres)

VC as $\mathrm{ml} / \mathrm{cm}$ height

$\mathrm{VC}$ as $\mathrm{L} / \mathrm{m}^{2}$ surface area

Peak Expiratory Flow (L/min)

PEF as L/cm height

PEF as L/kg weight

$P E F$ as $L / m^{2}$ surface area

$P E F$ as L/age in years

Grip Strength (kg) Right

Grip Strength (kg) Left

\section{Range}

18-24

$153.5-179.0$

45.0-69.0

$1.41-1.78$

$3.00-4.70$

18.5-30.6

2.08-3.03

455-655

2.88-3.53

7.84-12.11

282-394

20.6-31.6

28-46

$32-43$
The PEFR values show interesting differences which can be related to severity of training schedules (Saltin and Åstrand, 1967; De, et al, 1978). Top class athletes, as reported by Malhotra, et al, show significantly higher values for PEFR than in this study, however goalkeepers show about $7 \%$ higher average values than the norms for Indian populations and for physical education students (De, 1978; De, et al, 1978; Kamat, et al, 1967).

Measurements of grip strength are scarce and no practicable comparison can be made with population norms. However, data from Indian hockey players (Singh, 1978) and Volleyball and "Kabaddi" players (De, et al, 1979) show that goalkeepers have stronger GS and appear to show little difference between strengths of left and right hands. When compared with American athletes of similar age (Cureton, 1951) their GS is weaker in both hands. Since GS is not usually calculated in terms of height or weight it is probable that these differences may be related to the smaller stature of the Indian goalkeepers.

When VC is calculated in terms of surface-area derived from both height and weight, goalkeepers show higher values compared with published values for similar aged healthy Indians (Rao, et al, 1961; Jakhanwal and Mohanty, 1967; Bhargava, et al, 1973; Milledge, 1965; Malhotra, et al, 1972).

\section{ACKNOWLEDGEMENT}

I thank the members of the Wari Club, Calcutta for co-operating with me in conducting this work.

\section{REFERENCES}

Behnke, A. R. and Royce, J. 1966. "Body size, shape and body composition of several types of athletes". J.Sports Med. 6: 75-88.

Bhargava, R. P., Mishra, S. M. and Gupta, N. K. 1973. "Ventilatory tests and lung volume studies in Madhya Pradesh Physiological norms". Indian J.P.hysiol.Pharmacol. 17: 267-272.

Cureton, T. K. 1951. "Physical fitness of champion athletes". Urbana: University of Illinois Press: 458.

De, A. K. 1978. "Pulmonary Function Tests of the students of physical education". J. SNIPES (Soc.Nat.Inst.Physic.Ed. Sports) 1(1): 74-79.

De, A. K., Debnath, P. K., Roy, D. C. and Nagchaudhuri, J. 1978. "A comparison of physical efficiency between Indian physical education and medical students". Brit.J.Sports Med. 12: 93-96.

De, A. K., Debnath, P. K. and Nagchaudhuri, J. 1979. "A comparison of physical efficiency between female Volleyball and "Kabaddi" players". J. SNIPES (Soc.Nat.Inst.Physic.Ed.Sports) (communicated).

Di-Prampero, P. E., Pinera Limas, F., and Sassi, G. 1970. "Maximal muscular power, aerobic and anaerobic in 116 athletes performing at the XIXth Olympic games in Mexico". Ergonomics 13: 665-674.

Jakhanwal, D. P. and Mohanty, P. 1967. "Vital capacity in young Indian adults". Indian J.Physiol.Pharmacol. 11: 121-125.

Kamat, S. R., Thiruvengadam, K. V. and Rao, T. L. 1967. "A study of pulmonary function among Indians and assessment of the Wright Peak Flow Meter in relation to spirometry for field use". Amer.Rev.Res.Dis. 96: 707-716. 
Malhotra, M. S., Ramaswamy, S. S., Joseph, N. T. and Sengupta, J. 1972a. "Physiological assessment of Indian athletes". Indian J.Physiol.Pharmacol. 16: 55-62.

Malhotra, M. S., Ramaswamy, S. S., Joseph, N. T. and Sengupta, J. 1972b. "Functional capacity and body composition in different classes of Indian athletes". Ibid 16: 300-308.

Milledge, J. S. 1965. "Vital Capacity and Forced Expiratory Volume in one second in South Indian Men". Indian J.Chest Dis. 7: 97-103.

Newman, F., Smalley, B. F. and Thomson, M. L. 1962. "Effect of exercise, body and lung size on co-diffusion in athletes and non-athletes". J.Appl.Physiol. 17: 649-655.

Novak, L. P., Hyatt, R. E. and Alexander, J. F. 1968. "Body composition and physiological functions in athletes". J.Amer.Med.Asson. 205: 764-770..

Rao, M. N., Sengupta, A., Saha, P. B. and Sitadevi, A. 1961. "Norms in Indians - pulmonary capacities in health". ICMR, Research S. (38): Series C.

Saltin, B. and Åstrand, P. O. 1967. “Maximal oxygen uptake in athletes”. J.Appl.Physiol. 23: 353-358.

Singh, K. 1978. “Physical fitness of Hockey players". J. SNIPES (Soc.Nat.Inst.Physic.Ed.Sports) 1(1): 29-32.

Sprynarova, S. and Parizkova, J. 1971. "Functional capacity and body composition in top weight-lifters, swimmers, runners and skiers". Int.Z.angew.Physiol. 29: 184-194. 